\title{
МОДУЛЯЦІЯ НАПРЯМКУ ВИПРОМІНЮВАННЯ ГЕТЕРОЛАЗЕРА 3 КВАНТОВИМИ ТОЧКАМИ InAs ПІД ВПЛИВОМ АКУСТИЧНОЇ ХВИЛІ
}

\author{
Р.М. ПЕЛЕЩАК, О.О. ДАНЬКІВ, О.В. КУЗИК
}

УДК 539.12-164 + 539.3

(c) 2012
Дрогобицький державний педагогічний університет ім. I. Франка

(Вул. I. Франка, 24, Дрогобич 82100, Лъвівсъка обл.; e-mail: peleshchak@ rambler. ru)
Побудовано теоретичну модель процесу модуляції напрямку випромінювання гетеролазера InAs/GaAs з квантовими точками InAs під впливом акустичної хвилі. Встановлено характер залежності амплітуди кута відхилення гетеролазера від частоти акустичної хвилі та геометричних розмірів квантової точки.

\section{1. Вступ}

Подальший прогрес в області гетеролазерів пов'язаний з використанням в активній області структур з квантовими точками (KT) [1, 2]. Напівпровідникові гетероструктури InAs/GaAs з KT InAs мають високий квантовий вихід фотолюмінесценції і $е$ перспективними матеріалами для створення лазерів у близькій інфрачервоній області спектра $[1,3]$. Лазери на KT виявляють значно кращі властивості, ніж лазери на квантових ямах. Вони мають більший коефіцієнт підсилення, цілком нечутливі до температури гратки, для них легше здійснювати контроль енергії кванта випромінювальної рекомбінації [4]. Істотно покращити властивості таких лазерів вдалося за рахунок отримання тунельно-зв'язаних у вертикальному напрямку KT [2, 5]. На рис. 1 наведено схему активної області гетеролазера, що містить KT InAs у матриці GaAs [6]. Такі лазери є, як правило, поверхневовипромінюючими лазерами з довжиною резонатора кілька довжин хвиль [6].

Джерела інфрачервоного випромінювання, які здатні швидко перебудовувати частоту генерації та напрямок випромінювання, є важливими елементами лазерної спектроскопії високої роздільної здатності та оптичних систем зв'язку $[5,7,8]$.

Важливим фактором, який впливає на спектральні характеристики гетеролазера, зокрема на стан поляризації світла [9], напрямок випромінювання [8], є пружні деформації матеріалу гетероструктури.

У даній роботі побудовано теорію модуляції напрямку випромінювання гетеролазера на квантових точках під впливом акустичної хвилі.
Акустична хвиля, яка є джерелом пружної періодичної неоднорідної деформації, приводить до періодичної зміни компонентів тензора діелектричної проникності матеріалу гетероструктури. Таким чином, акустооптична взаємодія приводить не тільки до зміни коефіцієнта заломлення з часом, але й до його неоднорідного просторового розподілу у напрямку, перпендикулярному до резонатора. Тому з часом буде змінюватися напрямок випромінювання гетеролазеpa.

\section{2. Модель}

Розглянемо наногетеросистему InAs/GaAs з напруженими квантовими точками InAs, що зазнає впливу акустичної хвилі (рис. 2). У багатошаровій структуpi локальне поверхневе напруження, спричинене КT, акумулюється i, як наслідок, проявляє себе у вигляді стовпчикового розташування острівців (KT), що спостерігалось для InAs/GaAs [10]. Тому таку систему, яка $є$ активною областю оптичного резонатора, можна подати у вигляді циліндричної матриці GaAs 3

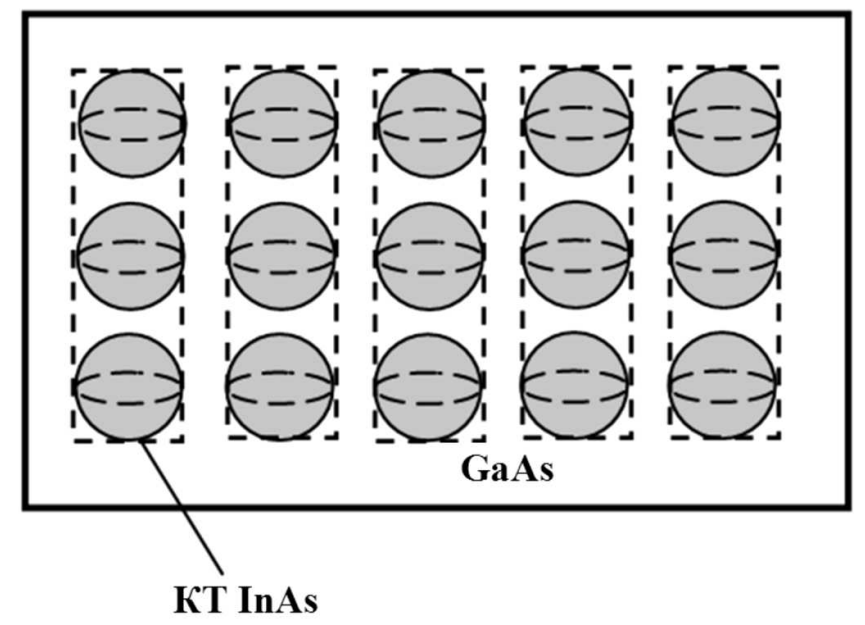

Рис. 1. Схема активної області гетеролазера InAs/GaAs з квантовими точками InAs 


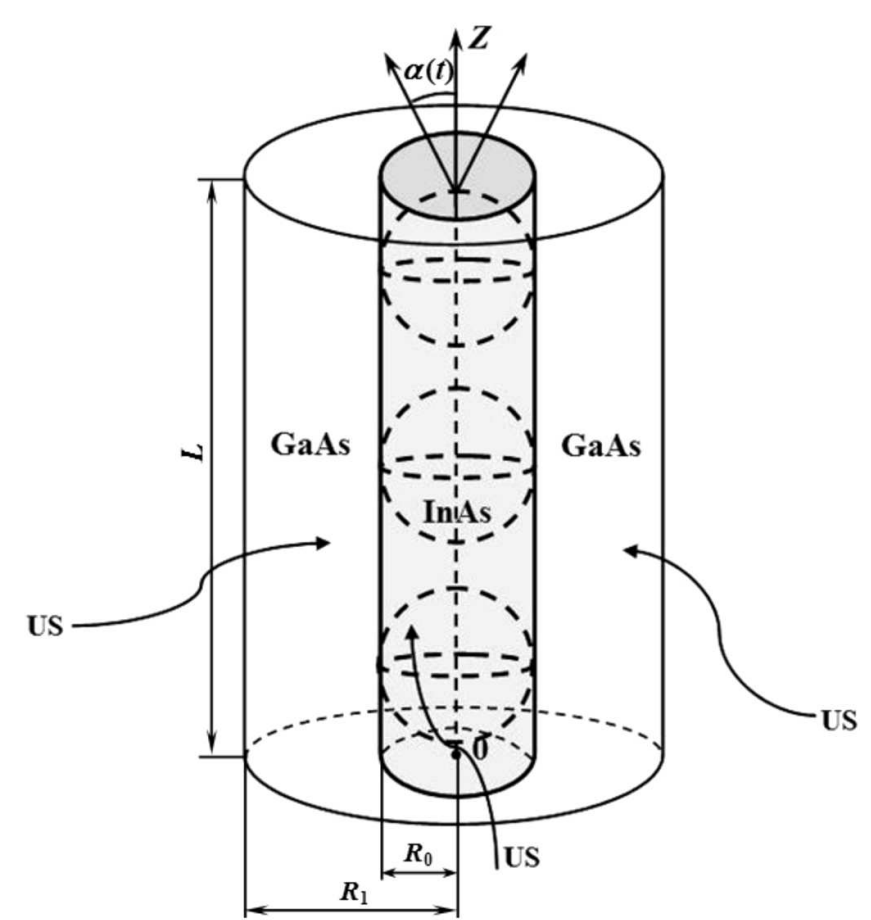

Рис. 2. Модель гетероструктури InAs/GaAs 3 тунельнозв'язаними у вертикальному напрямку KT InAs

радіусом основи $R_{1}$, в яку поміщено циліндр 3 радіусом основи, що дорівнює радіусу $\mathrm{KT} R_{0}$, та висотою $L$, яка дорівнює довжині резонатора (рис. 2). Вісь циліндра збігається з напрямком оптичного випромінювання за відсутності акустичної хвилі, а кут $\alpha(t)$ $€$ кутом відхилення напрямку випромінювання гетеролазера під впливом неоднорідної деформації, яку створюе акустична хвиля.

Оскільки стала гратки нарощуваного матеріалу InAs $\left(a_{1}=0,608\right.$ нм) більша, ніж матриці GaAs $\left(a_{2}=0,565\right.$ нм), то при гетероепітаксійному нарощуванні InAs на шар GaAs в межах псевдоморфного росту матеріал InAs зазнає деформації стиску, a GaAs - розтягу. Таким чином, в гетеросистемі InAs/GaAs виникає деформація, яка спричинена як дією акустичної хвилі, так і невідповідністю параметрів граток контактуючих матеріалів.

Для визначення компонентів тензора деформації необхідно знайти вектори зміщень $\mathbf{u}^{(i)}(t, \mathbf{r})$ $\left(i=\left\{\begin{array}{l}1 \equiv \mathrm{InAs} \\ 2 \equiv \mathrm{GaAs}\end{array}\right)\right.$ у матеріалах квантової точки чи матриці, які задовольняють рівняння:

$\rho^{(i)} \frac{\partial^{2} u_{i}^{(i)}}{\partial t^{2}}=\sum_{j} \frac{\partial \sigma_{i j}^{(i)}}{\partial x_{j}}$ де $\rho^{(i)}, \sigma_{i j}^{(i)}$ - густина і компоненти тензора напружень матеріалів квантової точки чи матриці відповідно;

$\sigma_{i j}^{(i)}=K^{(i)} \sum_{k} \xi_{k k}^{(i)} \delta_{i j}+2 \mu^{(i)}\left(\xi_{i j}^{(i)}-\delta_{i j} \frac{1}{3} \sum_{k} \xi_{k k}^{(i)}\right)$,

де $K^{(i)}, \mu^{(i)}$ - модулі всебічного стиску і зсуву відповідно, $\xi_{i j}^{(i)}$ - компоненти тензора деформації:

$\xi_{i j}^{(i)}=\frac{1}{2}\left(\frac{\partial u_{i}}{\partial x_{j}}+\frac{\partial u_{j}}{\partial x_{i}}\right)$.

Подамо вектори зміщень $\mathbf{u}^{(i)}(t, \mathbf{r})$ у вигляді суми двох доданків $\mathbf{u}^{(i)}(t, \mathbf{r})=\mathbf{u}_{l}^{(i)}(t, \mathbf{r})+\mathbf{u}_{T}^{(i)}(t, \mathbf{r})$, які задовольняють умови:

$\operatorname{rot} \mathbf{u}_{l}^{(i)}(t, \mathbf{r})=0, \quad \operatorname{div} \mathbf{u}_{T}^{(i)}(t, \mathbf{r})=0$.

У результаті отримаємо

$\Delta \mathbf{u}_{l}^{(i)}=\frac{1}{c_{l}^{(i) 2}} \frac{\partial^{2} \mathbf{u}_{l}^{(i)}}{\partial t^{2}}, \quad \Delta \mathbf{u}_{T}^{(i)}=\frac{1}{c_{T}^{(i) 2}} \frac{\partial^{2} \mathbf{u}_{T}^{(i)}}{\partial t^{2}}$,

де $c_{l}^{(i)}=\sqrt{\frac{3 K^{(i)}+4 \mu^{(i)}}{3 \rho^{(i)}}}, c_{T}^{(i)}=\sqrt{\frac{\mu^{(i)}}{\rho^{(i)}}}-$ поздовжні та поперечні швидкості акустичних коливань у матеріалах квантової точки чи матриці.

Поперечна акустична хвиля $\left(\mathbf{u}_{T}^{(i)}\right)$ у (4) не приводить до зміни об'єму [11], оскільки $\operatorname{div} \mathbf{u}_{T}^{(i)}(t, \mathbf{r})=0$. Поширення поздовжньої хвилі супроводжується об'ємним розширенням та стиском.

Пружні коливання у гетеросистемі з квантовими точками розглядатимемо на фоні статичних напружень, що виникають за рахунок невідповідності параметрів граток контактуючих матеріалів. Наведемо зміщення у вигляді

$\mathbf{u}_{l}^{(i)}(\mathbf{r}, t)=\mathbf{u}_{0}^{(i)}(\mathbf{r})+\mathbf{u}_{1 l}^{(i)}(\mathbf{r}, t)$,

де $\mathbf{u}_{0}^{(i)}(\mathbf{r})$ - статичні зміщення у матеріалі квантової точки чи матриці, які виникають за рахунок невідповідності параметрів граток контактуючих матеріалів. Оскільки в роботі проводиться розрахунок кута відхилення випромінювання гетеролазера, то обмежимось розрахунком складової зміщень $\mathbf{u}_{1 l}^{(i)}(\mathbf{r}, t)$ у матеріалах квантової точки чи матриці, які спричинені дією акустичної хвилі.

Для аксіально симетричної системи радіальне напруження має вигляд

$\sigma_{r r}^{(i)}=\left(K^{(i)}+\frac{4}{3} \mu^{(i)}\right) \frac{\partial u_{r}^{(i)}}{\partial r}+\left(K^{(i)}-\frac{2}{3} \mu^{(i)}\right) \frac{u_{r}^{(i)}}{r}$. 
Перейшовши до скалярного потенціалу $\mathbf{u}_{1 l}^{(i)}=$ $\nabla \varphi^{(i)}$, рівняння (4) з урахуванням (5) можна записати у вигляді

$\Delta \varphi^{(i)}=\frac{1}{c_{l}^{(i) 2}} \frac{\partial^{2} \varphi^{(i)}}{\partial t^{2}}$.

Розв'язок рівняння (7) шукаємо в кожній області гетероструктури з урахуванням крайових умов

$$
\left\{\begin{array}{l}
\left.\sigma_{r r}^{(1)}(t)\right|_{r=R_{0}}=\left.\sigma_{r r}^{(2)}(t)\right|_{r=R_{0}} \\
\left.u_{r}^{(1)}(t)\right|_{r=R_{0}}=\left.u_{r}^{(2)}(t)\right|_{r=R_{0}} \\
\left.\sigma_{r r}^{(2)}(t)\right|_{r=R_{1}}=-\sigma_{u s} \sin \omega t .
\end{array}\right.
$$

Остання крайова умова системи (8) визначає вплив акустичної хвилі на напружений стан наносистеми як дію періодичної вимушуючої сили з частотою $\omega$, де $\sigma_{u s}$ - амплітуда механічного напруження, створеного акустичною хвилею на поверхні матриці. Напрямок цієї зовнішньої періодичної сили та пружної сили, що виникає у наногетеросистемі під її впливом, є протилежними у будь-який момент часу, що зумовлюе вибір знака у другому рівнянні системи (8).

Таким чином, враховуючи (6) - (8), а також те, що $u_{r}^{(i)}=\frac{\partial \varphi^{(i)}}{\partial r}$, отримуємо вираз для радіальних складових вектора зміщень у квантовій точці чи матриці:

$$
\begin{aligned}
& u_{r}^{(1)}(r, t)=C_{1} \frac{\omega}{c_{l}^{(1)}} J_{1}\left(\frac{\omega r}{c_{l}^{(1)}}\right) \sin \omega t, \\
& u_{r}^{(2)}(r, t)=C_{2} \frac{\omega}{c_{l}^{(2)}} J_{1}\left(\frac{\omega r}{c_{l}^{(2)}}\right) \sin \omega t+ \\
& +C_{3} \frac{\omega}{c_{l}^{(2)}} Y_{1}\left(\frac{\omega r}{c_{l}^{(2)}}\right) \sin \omega t
\end{aligned}
$$

де $J_{1}, Y_{1}$ - функції Бесселя 1-го та 2-го роду. Константи $C_{1}, C_{2}, C_{3}$ визначаються з крайових умов (8). При отриманні розв'язку (9) забезпечено регулярність функції в точці $r=0$.

Компоненти тензора деформації матеріалів квантової точки чи матриці такі:

$\xi_{r r}^{(i)}=\frac{\partial u_{r}^{(i)}}{\partial r^{(i)}}, \quad \xi_{\varphi \varphi}^{(i)}=\frac{u_{r}^{(i)}}{r^{(i)}}, \quad \xi_{z z}^{(i)}=-\frac{\nu^{(i)}}{1-\nu^{(i)}}\left(\xi_{r r}^{(i)}+\xi_{\varphi \varphi}^{(i)}\right)$

$\xi^{(i)}=\operatorname{Sp} \xi^{(i)}=\xi_{r r}^{(i)}+\xi_{\varphi \varphi}^{(i)}+\xi_{z z}^{(i)}$

де $\nu^{(i)}$ - коефіцієнт Пуассона матеріалу квантової точки чи матриці.

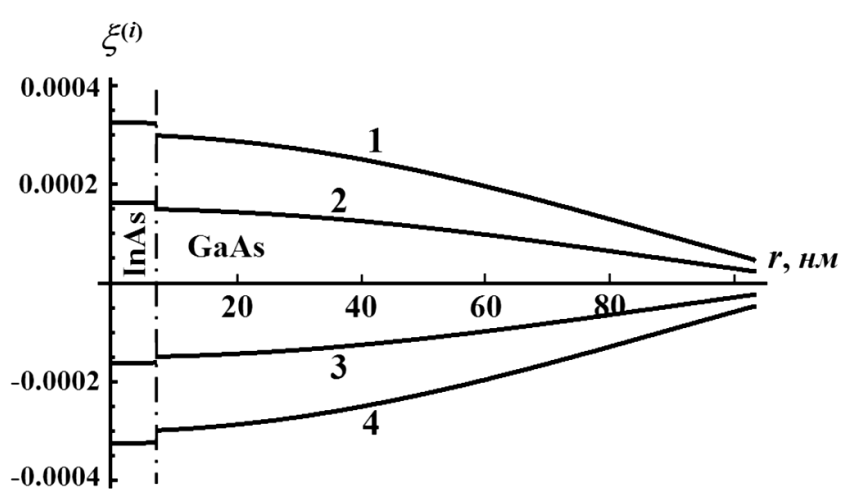

Рис. 3. Просторовий розподіл всебічної деформації $\xi(r)$ у матеріалах KT та матриці в різні моменти часу: $1-\omega t=\frac{\pi}{2} ; 2-$ $\omega t=\frac{\pi}{6} ; 3-\omega t=\frac{7 \pi}{6} ; 4-\omega t=\frac{3 \pi}{2}$

\section{3. Модуляція напрямку випромінювання гетероструктури з квантовими точками}

Розглянемо поширення світлового променя в гетероструктурі InAs/GaAs з квантовими точками InAs, що зазнає аксіально-симетричної деформації під впливом акустичної хвилі (рис. 2). На рис. 3 наведено результати розрахунків просторового розподілу всебічної деформації матеріалу гетероструктури InAs/GaAs 3 квантовими точками InAs у різні моменти часу при частоті акустичної хвилі $10^{9}$ Гц. Розрахунки проводили за таких значень параметрів [12]: $R_{1}=100 \mathrm{нм;} K^{(1)}=0,58$ Мбар; $\mu^{(1)}=$ 0,19 Мбар; $K^{(2)}=0,79$ Мбар; $\mu^{(2)}=0,33$ Мбар; $\rho^{(1)}=5680 \mathrm{K \Gamma} / \mathrm{M}^{3} ; \rho^{(2)}=5320 \mathrm{K \Gamma} / \mathrm{M}^{3} ; \nu^{(1)}=0,352 ;$ $\nu^{(2)}=0,318 ; \sigma_{u s}=10$ бар.

Вплив акустичної хвилі приводить до виникнення градієнта деформації, а отже, й показника заломлення у напрямку, перпендикулярному до оптичного резонатора. Як видно з рис. 3, за час, що дорівнює періоду акустичної хвилі, змінюється не тільки величина градієнта деформації, а і його напрямок. Тому очевидно, що з часом буде змінюватися траєкторія світлового променя, яка у неоднорідному середовищі описується диференціальним рівнянням

$$
\frac{d^{2} r}{d z^{2}}=\frac{1}{n^{(i)}} \frac{d n^{(i)}}{d r}
$$

з крайовими умовами:

$\left\{\begin{array}{l}r(z=0)=r_{0} \\ \frac{d r(z=0)}{d z}=0\end{array}\right.$ 


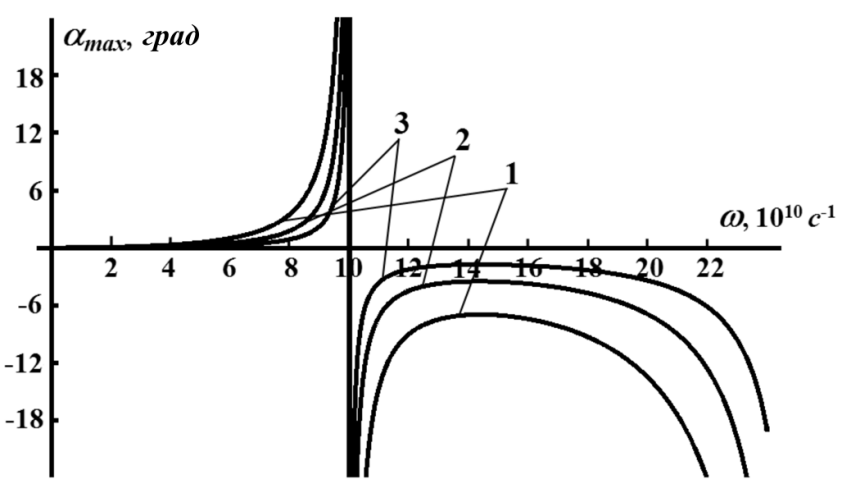

Рис. 4. Залежність амплітуди кута відхилення випромінювання гетеролазера InAs/GaAs з KT InAs від частоти акустичної хвилі для різних розмірів КТ: $1-R_{0}=3$ нм; $2-R_{0}=6$ нм; 3 $-R_{0}=9$ нм

Перша умова визначає початкову відстань $r_{0}$ променя від осі симетрії, друга умова вказує на те, що промені у площині $z=0$ поширюються паралельно до осі $O Z$.

Враховуючи те, що показник заломлення визначається співвідношенням $n^{(i)}(r, t)=\sqrt{\varepsilon^{(i)}(r, t)}\left(\varepsilon^{(i)}(r, t)\right.$ - діелектрична проникність матеріалу гетероструктури), рівняння (12) можна переписати у вигляді

$\frac{d^{2} r}{d z^{2}}=\frac{1}{2 \varepsilon_{0}^{(i)}} \frac{d \varepsilon^{(i)}}{d r}$

де $\varepsilon_{0}^{(i)}$ - діелектрична проникність однорідного матеріалу гетероструктури.

Діелектричну проникність $\varepsilon^{(i)}(r, t)$ матеріалу $\mathrm{KT}$, що змінюється з часом під дією акустичної хвилі, можна подати у вигляді [13]:

$\varepsilon^{(i)}(r, t)=\varepsilon_{0}^{(i)}+a^{(i)} \xi^{(i)}(r, t)$,

де $a^{(i)}<0$ - пружнооптичні сталі.

3 урахуванням (9), (11) та (15) у наближенні $\frac{\omega r}{c_{l}^{(1)}} \ll 1$ рівняння (14), що описує траєкторію променя у внутрішньому циліндрі (рис. 2), можна записати у вигляді

$\frac{d^{2} r}{d z^{2}}=\frac{1}{4 \varepsilon_{0}^{(1)}} a^{(1)} \frac{1-2 \nu^{(1)}}{1-v^{(1)}} C_{1}\left(\frac{\omega}{c_{l}^{(1)}}\right)^{4} r \sin \omega t$.

Розв'язок диференціального рівняння (16) з урахуванням крайових умов (13):

$r(z, t)=r_{0} \cos \sqrt{|q| \sin \omega t} z$,

$2 \pi n \leq \omega t \leq(2 n+1) \pi, \quad n=0,1,2, \ldots$ $r(z, t)=r_{0} \operatorname{ch} \sqrt{q \sin \omega t} z$,

$(2 n+1) \pi \leq \omega t \leq 2 \pi(n+1)$,

де

$q=\frac{a^{(1)}}{4 \varepsilon_{0}^{(1)}} \frac{1-2 v^{(1)}}{1-v^{(1)}} C_{1}\left(\frac{\omega}{c_{l}^{(1)}}\right)^{4}$.

При виході з оптичного резонатора довжиною $L$ амплітуда кута відхилення $\alpha_{\max }$ випромінювання гетеролазера від початкового напрямку поширення дорівнюватиме

$\operatorname{tg} \alpha_{\max }=\frac{d r(z=L)}{d z}=r_{0} q\left(\omega, R_{0}\right) L$

або з урахуванням того, що $\sqrt{|q|} L \ll 1$ :

$\alpha_{\max } \approx r_{0} q\left(\omega, R_{0}\right) L$

Як бачимо, кут відхилення променя пропорційний до його відстані від аксіальної осі, а отже, оптичний резонатор, що піддається впливу акустичної хвилі поводить себе як лінза (півперіоду як збиральна, а іншу половину - як розсіювальна) з фокусною відстанню $f= \pm \frac{1}{|q| L \sqrt{|\sin \omega t|}}$, що змінюється з часом.

На рис. 4 подано залежність амплітуди кута відхилення випромінювання гетеролазера InAs/GaAs 3 квантовими точками InAs від частоти акустичної хвилі при різних значеннях радіуса квантової точки $\left(\varepsilon_{0}^{(1)}=12,8 ; L=2\right.$ мкм; $\left.r_{0}=1 \mathrm{MKM}\right)$.

Акустооптична стала $a^{(i)}$ може бути визначена 3 експерименту. При проведенні розрахунків стала $a^{(i)}$ вибиралась таким чином, щоб амплітуда кута відхилення випромінювання гетеролазера InAs/GaAs 3 квантовими точками InAs радіусом 3 нм при частоті акустичної хвилі $10^{10}$ Гц становила $3^{\circ}$.

Амплітуда модуляції напрямку випромінювання визначається величиною градієнта деформації, який залежить як від частоти акустичної хвилі, так і від амплітуди деформації. При збільшенні частоти акустичної хвилі в діапазоні $10^{7} \mathrm{c}^{-1}<\omega<6 \cdot 10^{10} \mathrm{c}^{-1}$ амплітуда кута відхилення зростає за законом $\alpha_{\max } \sim$ $\omega^{3}$. За подальшого збільшення частоти акустичної хвилі спостерігається немонотонна зміна кута відхилення випромінювання гетеролазера з максимумом, що відповідає частоті $\omega \approx 10^{11} \mathrm{c}^{-1}$, що пов'язане із зростанням амплітуди деформації матеріалу КT. Таке зростання деформації відбувається внаслідок наближення частоти акустичної хвилі до власної частоти коливань атомів KT [14]. Розбіжність розв'язку 
при $\omega \approx 10^{11} \mathrm{c}^{-1}$ зумовлена нехтуванням загасання коливань у пружному середовищі.

При частоті акустичної хвилі з діапазону $10^{7} \mathrm{c}^{-1}<$ $\omega<5 \cdot 10^{10} \mathrm{c}^{-1}$ амплітуда модуляції напрямку випромінювання гетеролазера InAs/GaAs з KT InAs практично не залежить від їх розмірів. Для частоти акустичної хвилі $\omega>5 \cdot 10^{10} \mathrm{c}^{-1}$ спостерігається монотонне збільшення кута відхилення при зменшенні радіуса КТ. Це пояснюється тим, що квантові точки менших розмірів є більш чутливими до впливу зовнішнього механічного напруження.

\section{4. Висновки}

1. Побудовано теоретичну модель процесу модуляції напрямку випромінювання гетеролазера InAs/ GaAs з квантовими точками InAs під дією акустичної хвилі. 2. Встановлено, що при збільшенні частоти акустичної хвилі в діапазоні $10^{7} \mathrm{c}^{-1}<\omega<5 \cdot 10^{10} \mathrm{c}^{-1}$ амплітуда кута відхилення напрямку випромінювання гетеролазера монотонно зростає за законом $\alpha_{\max } \sim \omega^{3}$, а при частоті $\omega>5 \cdot 10^{10} \mathrm{c}^{-1}$ така залежність має немонотонний характер.

3. Показано, що при зменшенні розміру КТ амплітуда модуляції напрямку випромінювання гетеролазеpa InAs/GaAs зростає, що пояснюється збільшенням градієнта деформації матеріалу КТ.

1. N.N. Ledentsov, Semicond. Sci. Technol. 78, 014001 (2011).

2. Ю.М. Шерняков, А.Ю. Егоров, А.Е. Жуков, С.В. Зайцев и др., Письма в ЖТФ 23, 51 (1997).

3. E. Stock, M.-R. Dachner, T. Warming, A. Schliwa, Phys. Rev. B 83, 041304 (2011).

4. Y. Arakawa and H. Sakaki, Appl. Phys. Lett. 40, 939 (1982).

5. А.М. Надточий, С.А. Блохин. А. Мутиг, Дж. Лотт и др., ФТП 45, 688 (2011).

6. А.Н. Пихтин, Оптическая и квантовая электроника (Высшая школа, Москва, 2001).

7. Л.А. Кулакова, ФТТ 51, 73 (2009).

8. Л.А. Кулакова, А.В. Лютецкий, В.Б. Волошинов, Письма в ЖТФ 36, 48 (2010).

9. О.И. Котов, А.В. Хлыбов, Л.Б. Лиокумович, С.И. Марков и др., ЖТФ 76, 101 (2006).
10. Q. Xie, A. Madhukar, and P. Chen, Phys. Rev. Lett. 75, 2542 (1995).

11. Л.Д. Ландау, Е.М. Лифшиц, Теория упругости (Наука, Москва, 1987).

12. G. Van de Walle, Phys. Rev. B 39, 1871 (1989).

13. Л.Д. Ландау, Е.М. Лифшиц, Электродинамика сплошных сред (Наука, Москва, 1982).

14. Р.М. Пелещак, О.О. Даньків, О.В. Кузик, Журнал фізичних досліджень 14, 4402 (2010).

Одержано 23.05.11

\section{МОДУЛЯЦИЯ НАПРАВЛЕНИЯ ИЗЛУЧЕНИЯ \\ ГЕТЕРОЛАЗЕРА InAs/GaAs C КВАНТОВЫМИ \\ ТОЧКАМИ InAs ПОД ВЛИЯНИЕМ \\ АКУСТИЧЕСКОЙ ВОЛНЫ}

Р.М. Пелещак, О.О. Данъкив, О.В. Кузык

$\mathrm{P}$ е $з$ ю м е

Построена теоретическая модель процесса модуляции направления излучения гетеролазера InAs/GaAs c квантовыми точками InAs под влиянием акустической волны. Установлен характер зависимости амплитуды угла отклонения гетеролазера от частоты акустической волны и геометрических размеров квантовой точки.

MODULATION OF THE DIRECTION

OF RADIATION EMITTED BY AN InAs/GaAs HETEROLASER WITH InAs QUANTUM DOTS UNDER THE INFLUENCE OF ACOUSTIC WAVE

R.M. Peleshchak, O.O. Dan'kiv, O.V. Kuzyk

Ivan Franko Drohobych State Pedagogical University (24, Ivan Franko Str., Drohobych 82100, Lviv region, Ukraine; e-mail: peleshchak@rambler.ru)

$\mathrm{S}$ u m m a r y

A theoretical model describing the modulation of a direction of radiation emitted by an InAs/GaAs heterolaser with InAs quantum dots under the influence of an acoustic wave has been developed. The character of the dependences of the emission deviation angle on the acoustic wave frequency and the geometric sizes of quantum dots has been determined. 